\title{
The Effect of Forward Head Posture and Tension Type Headache on Neck Movement: For Office Worker
}

\author{
In-Gyun Kim', Sang-Yeol Lee² \\ ${ }^{1}$ Department of Physical Therapy, Graduate School of Clinical Pharmacy and Health, Kyung-Sung University, Busan; ${ }^{2}$ Department of Physical \\ Therapy, Kyung-Sung University, Busan, Korea
}

Purpose: This study examined the effects of the forward head posture and tension type headache on neck movement among office workers.

Methods: The subjects were 6 male and 21 female patients composed of a forward head posture group, forward head posture group with a tension type headache and a normal group. Each group consisted of 2 males and 7 females. The cranio-vertebral angle of the head and the angle of motion of the neck were measured. SPSS 23.0 was used for data analysis and one-way ANOVA was performed for the mean comparison of the neck movements in the three groups.

Results: The participants had a limitation in the movement of all necks between the forward head posture group and forward head posture with tension type headache group compared to the normal subjects. The forward head posture with tension headache group had limited neck extension and lateral bending compared to the forward head posture group.

Conclusion: Office workers have limitations in the movement of the neck when they are accompanied by forward head posture and tension headache. In particular, when accompanied with a tension headache, there is a restriction on the neck extension and side bending. This study is expected to provide basic data for the relief of tension headache and the treatment of forward head posture in office workers.

Keywords: Cervical range of motion, Tension type headache, Forward head posture

\section{서 론}

생활환경이 점차 사무화, 자동자화로 변함에 따라 현대인들은 장시 간 컴퓨터 작업이 증가하고 있다. 이로 인한 신체활동의 감소로 각종 질환의 위험에 노출되어 있다. 특히 반복적인 동작, 부적절한 작업 자 세, 무리한 힘의 사용, 날카로운 면과의 신체접촉, 진동 및 온도 등의 요인에 의하여 발생되는 목, 어깨, 허리 상. 하지의 신경· 근육 및 그 주 변 신체조직 등에 나타나는 질환이 나타난다. ${ }^{1}$ 이러한 질환은 통증 및 관절 기능 제한 등의 건강상 문제를 야기시키며 이와 같은 증상을 근골격계 장애(musculoskeletal disorder, MSD)라고 한다. ${ }^{2}$

우리나라 사무직 종사자들의 평균 근무시간은 연평균 2,057시간 (일평균 5.7 시간)이다. 특히 사무직종사자들은 컴퓨터 사용이 늘어나 면서 정적인 자세로 오랜 시간 반복적으로 원위부 지절을 사용하여 키보드를 쳐야 하는 상황이 근골격계 장애를 발생시킨다. 또한 컴퓨 터의 장시간 사용은 정적이며, 매우 반복적으로 근육에 부하가 발생
한다. 이러한 경우 근육의 과도한 활동, 인대의 긴장, 관절의 해부학적 관계 변화로 인해 목과 어깨 및 주변부의 통증을 초래하게 된다. ${ }^{5}$

이러한 사무직종사자들에서 자주 발생하는 자세 변위는 두부 전 방전위 자세이다. 이는 중력중심선 앞으로 머리가 이동하여 만성화되 는 것인데 다양한 근골격계와 신경혈관 기능장애를 일으킬 수 있는 요인으로 작용한다. 두부 전방전위 자세는 아래 목뼈와 위 등뼈의 증 가 된 굽힘, 고리뼈와 뒤통수의 증가된 폄, 위 목뼈의 증가된 폄이 특징 적이며, 반복 사용 긴장성 증후군 같은 직업적 증후군의 진행과정 중 특정근육의 지속적 긴장에 기인하여 두부 전방전위 자세의 변화를 초래하게 된다. 이러한 두부 전방전위 자세는 긴장성 두통, 경부통증, 경추성 두통, 그리고 편측성 편두통과 연관이 있다.1-10 특히 두부 전방 전위 자세의 긴장성 두통은 목의 움직임이 정상인에 비해 제한되어 있다." 이렇듯 사무직종사자들은 컴퓨터를 장시간으로 사용하면서 두부전방전위가 나타나며, ${ }^{5}$ 이러한 자세는 긴장성 두통을 유발하며, 정상인에 비해 목의 움직임이 제한되는 문제를 일으키고 있다? 
하지만 대부분의 연구들은 대상자 선정에 있어 일반인 혹은 불특 정 직업군의 두부 전방전위 환자 혹은 긴장성 두통 환자를 대상으로 하였기에 대상자의 직업적 특색에 따라 정확한 통제가 이루어지지 않아 연구에 신뢰성에 의문점을 가질 수 있다. 또한 두부 전방전위 자 세와 긴장성 두통으로 인한 목의 움직임 제한을 명확하게 구분할 수 있는 연구가 부족하다.

따라서 본 연구 대상자(두부전방전위 환자와 두부 전방전위 자세 를 동반한 긴장성 두통 환자)의 선정에 있어 특정 직업군인 사무직종 사자를 선정하였으며, 두부 전방전위 자세 환자와 긴장성 두통 환자, 그리고 정상인으로 그룹을 나누어 목의 움직임에 대한 각 그룹 간에 차이를 확인할 것이며, 추후 긴장성 두통의 치료적 중재 연구에 기초 자료로 사용하고자 한다.

\section{연구 방법}

\section{1. 연구대상}

본 연구는 한 달 동안 창원 00 한방병원에 내원한 단순 근골격 환자 중 목의 움직임 큰 문제가 없는 자발적으로 참여를 원한 성인 남성과 여성 27명을 대상으로 실시하였다. 대상자는 각각 9명씩 증상에 따라 3 그룹으로 선정하였다. 두부 전방 전위 증상은 Nemmers 등12 연구에 의해 전방 전위 각도 $50^{\circ}$ 이하인 대상자로 선정하였으며, 남녀의 성비 는 모든 그룹에서 2:7로 하였다. 정상인 그룹을 포함한 모든 대상자는 하루 5시간 이상 컴퓨터를 사용하는 사무직 종사자로 하였으며, 긴 장성 두통을 동반한 대상자는 국제두통협회 ${ }^{13}$ 에서 제공한 자료를 통 하여 긴장성 두통 유무를 확인한 후 선정하였다.

대상자 제외 기준은 다음과 같다. 목과 머리에 문제가 있는 자, 목 을 움직이기 힘들 정도의 통증이 있거나 심각한 목 손상 환자, 두통 을 완화시키는 약물을 복용하고 있는 자, 실험 중 통증을 호소하거나 실험을 거절한 자는 제외하였다. 경성대학교 연구윤리위원회로부터 승인을 받은 연구이다.

\section{2. 실험방법}

본 연구는 두부 전방전위 자세 그룹, 두부 전방 전위와 긴장성 두통 을 동반한 그룹 그리고 사무직 종사자들 중 정상 그룹으로 나누어 측 정하였다. 대상자는 편안하게 의자에 앉은 상태에서 두부 전방전위 자세 각도와 능동적 목의 움직임 각도를 측정하였다.

두부 전방전위 자세 각도의 측정은 실험자가 편안하게 앉은 상태 에서 귀의 이주(tragus)와 C7의 가시돌기 마커를 하고, C7을 지나는 수평선과 귀의 이주와 제7목뼈 가시 돌기 사이를 연결한 선이 형성하 는 각도를 측정하였다(Figure 1).

목의 움직임 각도는 앉은 자세에서 굽힘과 폄, 오른쪽. 왼쪽의 측면

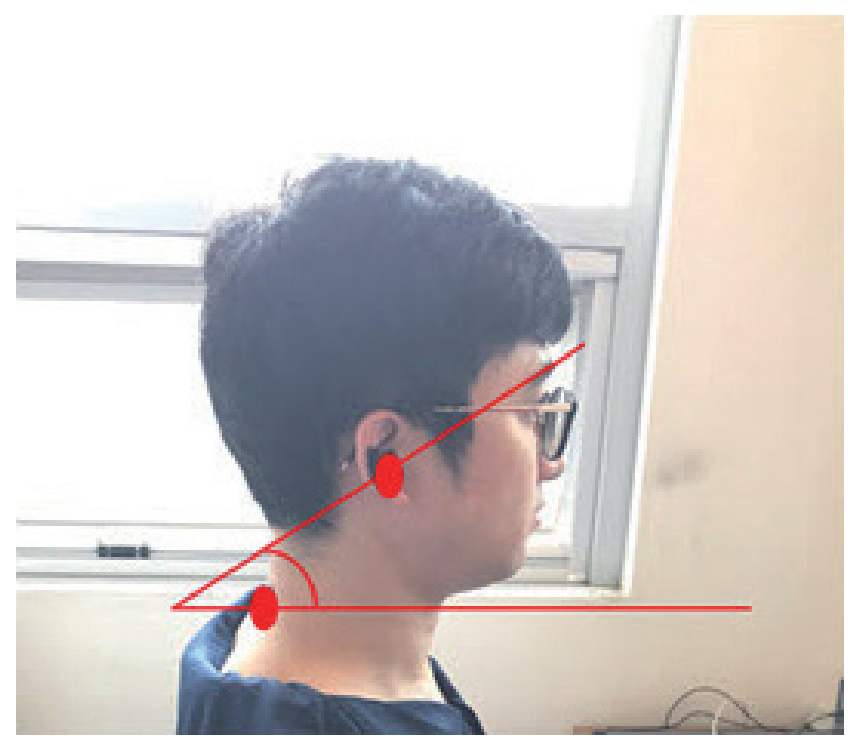

Figure 1. The cranio-vertebral angle: the angle between $\mathrm{C} 7$ and tragus.

굽힘, 오른쪽 왼쪽의 회전을 능동적으로 시행하는 동안 검사자가 순 수한 목의 움직임 각도가 평가 가능한 전자각도계(J Tech Dualer IQ Dual Inclinometer, USA)를 이용하여 목의 움직임 각도를 측정하였다. 검사 자세는 가슴 척추를 등받이 의자에 최대한 밀착시킨 상태에서 목의 움직임 시 가슴 척추에 움직임이 없도록 고정식 벨트로 몸통을 고정 후 메인 센서는 이마에 위치시키고, 두 번째 센서는 목 척추 7번 에 위치시킨 후 목의 움직임을 측정한다. 3 번 측정 후 평균 값을 평균 값을 지정하였다.

\section{3. 통계 처리}

자료 처리를 위해 window SPSS PC (ver 23.0)를 사용하였다. 3개 그룹 (정상 그룹, 두부 전방전위 자세 그룹, 두부 전방전위 자세를 동반한 긴장성 두통 그룹)에서 나타나는 목의 움직임 각도와 두부 전방 전위 자세 각도를 비교하기 위해 일원배치분산분석(one-way ANOVA)을 실시하였다. 통계적 유의 수준 $\alpha$ 는 0.05 로 하였다.

\section{결 과}

본 연구는 사무직종사자들 중 두부 전방전위 자세와 긴장성 두통을 동반한 두부 전방전위 자세가 목의 움직임에 미치는 영향을 알아보 고자 연구를 진행하였다.

\section{1. 연구대상의 일반적 특성}

연구대상자는 남자 6 명, 여자 21명으로 각 그룹 당 남자 2 명, 여자 7명 으로 구성하였다. 평균 나이는 정상 그룹은 $28.43 \pm 6.51$ 세, 두부 전방 전위 자세 그룹은 $27.95 \pm 5.04$ 세, 두부 전방전위를 동반한 긴장성 두 
Table 1. Indivisuals of subjects

\begin{tabular}{lcccc}
\hline & Normal $(n=9)$ & $\operatorname{FHP}(n=9)$ & FHP+TTH $(n=9)$ & $p$ \\
\hline Year & $28.43 \pm 6.51$ & $27.95 \pm 5.04$ & $29.00 \pm 5.53$ & 0.93 \\
$\mathrm{CVA}^{\circ}\left({ }^{\circ}\right)$ & $57.25 \pm 4.58$ & $42.12 \pm 7.11$ & $41.54 \pm 8.23$ & 0.84 \\
\hline
\end{tabular}

Each value represents the mean \pm SD.

FHP: forward head posture, TTH: tension type headache, CVA: cranio vertebral angle.

Table 2. Comparison of the cranio-vertebral angle each of group

\begin{tabular}{lccc}
\hline Normal $(n=9)$ & FHP $(n=9)$ & FHP+TTH $(n=9)$ & $p$ \\
\hline $69.16 \pm 9.04$ & $41.00 \pm 6.02^{*}$ & $40.28 \pm 4.49^{*}$ & $0.00^{+}$ \\
\hline
\end{tabular}

${ }^{*}$ Significant difference in a normal group; ${ }^{\dagger} p<0.05$.

Each value represents the mean \pm SD.

The values with different superscripts in the same column are different significantly $(p<0.05)$

통 그룹은 $29.00 \pm 5.53$ 세로 유의한 차이가 없었다( $\mathrm{p}>0.05$ )(Table 1). 두부 전방전위 자세 각도는 정상인 그룹은 $57.25 \pm 4.58$ 이었으며, 두부 전방전 위 자세 그룹은 $42.12 \pm 7.11$ 이었으며, 두부 전방전위를 동반한 긴장성 두 통 그룹은 $41.54 \pm 8.23$ 으로 유의한 차이가 없었다(p>0.05)(Table 1).

\section{2. 두부 전방전위 각도 비교}

각 그룹의 두부 전방전위 자세 각도를 측정한 결과, 정상 그룹 $69.16 \pm$ 9.04 , 두부 전방전위 자세 그룹 $41.00 \pm 6.02$, 두부 전방전위를 동반한 긴장성 두통 그룹 $40.28 \pm 4.49$ 로 세 그룹 간 유의한 차이를 보였다 ( $p>0.05$ )(Table 2). 사후 검정 결과 두부 전방전위 자세 그룹과 두부 전 방전위를 동반한 긴장성 두통 그룹이 정상 그룹에 비하여 유의한 전 방전위 각도를 보였다 $(\mathrm{p}<0.05)$ (Table 2).

\section{3. 경추 관절 가동 범위 비교}

각 그룹의 경추 관절 가동 범위를 측정한 결과, 굽힘은 정상 그룹 66.97 \pm 5.83 , 두부 전방전위 자세 그룹 $55.59 \pm 9.92$, 두부 전방전위를 동반한 긴 장성 두통 그룹 $50.45 \pm 7.06$ 으로 세 그룹 간 유의한 차이를 보였다. 사후 검정 결과, 세 그룹 모두 서로 유의한차이를 보였다( $\mathrm{p}<0.05$ )(Table 3). 폄 은 정상 그룹 $70.60 \pm 6.99$, 두부 전방전위 자세 그룹 $63.23 \pm 6.07$, 두부 전방전위를 동반한 긴장성 두통 그룹 $56.43 \pm 7.37$ 로 세 그룹 간 유의 한 차이를 보였다. 사후 검정 결과, 정상 그룹과 두부 전방전위를 동반 한 긴장성 두통 그룹, 정상 그룹과 두부 전방전위 자세 그룹 사이에 유의한차이를 보였다 $(\mathrm{p}<0.05)$ (Table 3$)$.

오른쪽 측면 굽힘은 정상 그룹 $42.88 \pm 1.90$, 두부 전방전위 자세 그 룹 $37.64 \pm 4.86$, 두부 전방전위를 동반한 긴장성 두통 그룹 $27.87 \pm 4.67$ 로 세 그룹 간 유의한 차이를 보였다. 사후 검정 결과, 세 그룹 모두 서 로 유의한 차이를 보였다 $(\mathrm{p}<0.05)$ (Table 3). 왼쪽 측면 굽힘은 정상 그 룹 $42.44 \pm 1.58$, 두부 전방전위 자세 그룹 $38.00 \pm 2.44$, 두부 전방전위 를 동반한 긴장성 두통 그룹 $29.00 \pm 3.60$ 으로 세 그룹 간 유의한 차이
Table 3. Comparing the range of motion of the cervical joints in each group

\begin{tabular}{|c|c|c|c|c|}
\hline & Normal $(n=9)$ & $\operatorname{FHP}(n=9)$ & $\begin{array}{c}\mathrm{FHP}+\mathrm{THH} \\
(\mathrm{n}=9)\end{array}$ & $p$ \\
\hline Flexion $\left(^{\circ}\right)$ & $.97 \pm 5.83$ & $55.59 \pm 9.92^{*}$ & $50.45 \pm 7.06^{\star+}$ & $0.00^{+}$ \\
\hline Extension $\left({ }^{\circ}\right)$ & $70.60 \pm 6.99$ & $63.23 \pm 6.07^{\star}$ & $56.43 \pm 7.37^{*}$ & $0.00^{+}$ \\
\hline $\begin{array}{l}\text { Right Lateral } \\
\text { bending }\left({ }^{\circ}\right)\end{array}$ & $42.88 \pm 1.90$ & $37.64 \pm 4.86^{*}$ & $27.87 \pm 4.67^{*+}$ & $0.00^{+}$ \\
\hline $\begin{array}{l}\text { Left Lateral } \\
\text { bending }\left({ }^{\circ}\right)\end{array}$ & 42. & $2.44^{*}$ & $29.00 \pm 3.60^{*+}$ & $0.00^{+}$ \\
\hline Right Rotation $\left({ }^{\circ}\right)$ & $82.88 \pm 2.85$ & $54.58 \pm 5.18^{*}$ & $57.46 \pm 11.73^{*}$ & $0.000^{+}$ \\
\hline Left Rotation $\left({ }^{\circ}\right)$ & $85.18 \pm 2.39$ & $60.95 \pm 7.81^{*}$ & $61.30 \pm 12.64^{*}$ & $0.00^{+}$ \\
\hline
\end{tabular}

*Significant difference in a normal group; ${ }^{+}$significant difference in a FHP group; ${ }^{*} p<0.05$

Each value represents the mean \pm SD

The values with different superscripts in the same column are different significantly $(p<0.05)$ by Tukey LSD measure.

를 보였다. 사후 검정 결과, 세 그룹 모두 서로 유의한 차이를 보였다 $(\mathrm{p}<0.05)$ (Table 3).

오른쪽 회전은 정상 그룹 $82.88 \pm 2.85$, 두부 전방전위 자세 그룹 $54.58 \pm 5.18$, 두부 전방전위를 동반한 긴장성 두통 그룹 $57.46 \pm 11.73$ 으 로 세 그룹 간 유의한 차이를 보였다. 사후 검정 결과, 정상 그룹과 두 부 전방전위를 동반한 긴장성 두통 그룹, 정상 그룹과 두부 전방전위 자세 그룹 사이에 유의한 차이를 보였다 $(\mathrm{p}<0.05)$ (Table 3). 왼쪽 회전 은 정상 그룹 $85.18 \pm 2.39$, 두부 전방전위 자세 그룹 $60.95 \pm 7.81$, 두부 전방전위를 동반한 긴장성 두통 그룹 $61.30 \pm 12.64$ 로 세 그룹 간 유의 한 차이를 보였다. 사후 검정 결과, 정상 그룹과 두부 전방전위를 동반 한 긴장성 두통 그룹, 정상 그룹과 두부 전방전위 자세 그룹 사이에 유의한 차이를 보였다 $(\mathrm{p}<0.05)$ (Table 3$)$.

\section{고 찰}

본 연구에서는 두부전방전위 자세를 가진 환자들 중 사무직에 종사 하는 직업군을 대상으로 실시하여 긴장성 두통이 목의 움직임에 미 치는 영향을 알아보고자 하였다. 특히 기존 선행논문들은 긴장성 두 통의 그룹을 지정함에 있어서 특정 직업군을 선택하지 않고 단순히 나이와 성별 차이에만 중점을 두고 연구하여 정확한 데이터 값을 얻 는 데 어려움이 있었다. 또한 긴장성 두통과 두부 전방전위 자세에 대 한 구분점이 명확하지 않아서 목의 움직임 제한이 긴장성 두통 때문 인지 두부 전방전위 자세 때문인지에 대한 의문점을 가지게 되었다. 본 연구에서는 이러한 단점을 보완하고자 하였다. 그 결과, 정상 그룹 에 비해 두부 전방전위를 동반한 긴장성 두통 그룹과 두부 전방전위 자세 그룹이 모든 목의 움직임 동작에서 높은 수치를 나타냈으며, 유 의성 차이에서도 정상 그룹과의 비교에서 유의한 차이를 보였다. 이 는 두부 전방전위 자세는 앞목갈비근, 상부 등세모근, 목 빗근의 단축 
과 어깨 올림근 및 머리반가시근의 늘어남을 가져오는 근육의 비정 상적인 근활성도를 유발시킨다.14 이로 인해 목의 척추 관절의 압박이 증가 ${ }^{15}$ 하여 목의 움직임에 제한을 가져 온 것으로 생각된다. 또한 두 부 전방전위 자세 그룹과 두부 전방전위를 동반한 긴장성 두통 그룹 간의 비교에서는 목의 폄과 측면 굽힘에서만 유의한 차이를 보였다. 이는 Fernández-de-las-Peñas 등 16 은 긴장성 두통 환자는 뒷머리 아래 근의 가로면적이 줄어든 위축이 나타난다고 하였으며, $\mathrm{Cho}^{17}$ 에 따르 면 긴장성 두통 환자는 MRI상으로 뒷머리아래근육인 작은 뒷머리 곧은근과 큰 뒷머리 곧은근의 가로 면적이 감소한다는 선행연구가 있었으므로 이러한 목의 폄과 측면굽힘 근육들이 동작에 제한을 가 져오는 큰 역할을 했을 것이라고 생각된다.

본 연구는 기존 연구들에 비해 긴장성 두통과 두부 전방전위를 동 반한 긴장성 두통 간의 목의 움직임에 차이를 확인할 수 있으며, 사무 직종사자들에게 특화된 논문이라고 볼 수 있다.

하지만 본 연구에 제한점은 연령층이 20-30대에 한정되어서 그 이 상의 연령대에는 적용하기 어려운 점과 남녀 비율이 차이가 나서 성 별에 따른 근육별 차이를 염두에 두지 않고 진행하였다. 또한 모집 단 위 인원이 너무 적어서 모든 사람들에게 일반화시키기에는 어려운 점이 있었으며 목의 움직임 측정에서 상부 목과 하부 목으로 따로 구 분 하지 않고 평가하여 목의 어느 부분에서의 제한이 되었는지 알 수 없었다. 이러한 제한점을 보완하여 추후 연구가 필요할 것이다.

\section{참고 문헌}

1. Korea Labor. Guideline for investigation of musculoskeletal disease burden task hazards. KOSHA. 2003.

2. Ong CN, Chia SE, Jeyaratnam J et al. Musculoskeletal disorders among operators of visual display terminals. Scand J Work Environ Health. 1995: 60-4.

3. Korea Occupational Safety Agency. Labor Environment Survey. 2016

4. Rossignol AM, Morse EP, Summers VM et al. Video display terminal use and reported health symptoms among Massachusetts clerical workers. J Occup Med. 1987;29(2):112-8.
5. Hagberg M, Wegman DH. Prevalence rates and odds ratios of shoulderneck diseases in different occupational groups. Br J Ind Med. 1987;44(9): 602-10.

6. Harrison DE, Harrison, DD, Cailliet R et al. Cobb method or Harrison posterior tangent method: which to choose for lateral cervical radiographic analysis. Spine. 2000;25(16):2072-8.

7. Fernández-de-las-Peñas C, Alonso-Blanco C, Cuadrado ML et al. Myofascial trigger points in the suboccipital muscles in episodic tension-type headache. Man Ther. 2006;11(3):225-30.

8. Silva AG, Punt TD, Sharples P et al. Head posture and neck pain of chronic nontraumatic origin: a comparison between patients and painfree persons. Arch Phys Med Rehabil. 2009;90(4):669-74.

9. Yip CHT, Chiu TTW, Poon ATK. The relationship between head posture and severity and disability of patients with neck pain. Man Ther. 2008;13(2):148-54.

10. Moore MK. Upper crossed syndrome and its relationship to cervicogenic headache. J Manipulative Physiol Ther. 2004;27(6):414-20.

11. Fernández-de-las-Peñas C, Cuadrado ML, Pareja JA. Myofascial trigger points, neck mobility, and forward head posture in episodic tensiontype headache. Headache. 2007;47(5):662-72.

12. Nemmers TM, Miller JW, Hartman MD. Variability of the forward head posture in healthy community-dwelling older women. J Geriatr Phys Ther. 2009;32(1):10-4.

13. Headache Classification Committee of the International Headache Society. Classification and diagnostic criteria for headache disorders, cranial neuralgias and facial pain. Cephalalgia. 1988;8 Suppl 7:1-96.

14. Finley, MA, Raymond YL. Effect of sitting posture on 3-dimensional scapular kinematics measured by skin-mounted electromagnetic tracking sensors. Archives of physical medicine and rehabilitation. 2003; 84(4):563-8.

15. van Duijn J, van Duijn AJ, Nitsch W. Orthopaedic manual physical therapy including thrust manipulation and exercise in the management of a patient with cervicogenic headache: a case report. J Man Manip Ther. 2007;15(1):10-24.

16. Fernández-de-las-Peñas C, Cuadrado ML, Arendt-Nielsen L et al. Myofascial trigger points and sensitization: an updated pain model for tension-type headache. Cephalalgia. 2007;27(5);383-93.

17. Cho SH. The effect of myofascial release technique and forward head posture correction exercise on chronic tension-type headache. Catholic University of Busan. Dissertation of Doctorate Degree. 2014. 